\title{
A GLOBALIZAÇÃO, O FIM DOS DIREITOS HUMANOS E A EXPERIÊNCIA DO SISTEMA INTERAMERICANO DE PROTEÇÃO DOS DIREITOS HUMANOS
}

\author{
THE END OF HUMAN RIGHTS AND THE REALITY OF THE INTER- \\ AMERICAN HUMAN RIGHTS SYSTEM
}

\section{Rafael Osvaldo Machado Moura}

Mestre em Direito pelo Programa de Pós-graduação em Direito da Pontifícia Universidade Católica do Paraná. É promotor de Justiça no Estado do Paraná.

E-mail: rafa.osmoura@gmail.com

Recebido em: 05/10/2015

Aprovado em: 31/03/2016

Doi: $10.5585 / \mathrm{rdb} . v 13 i 6.302$

RESUMO: O advento dos Sistemas normativos internacionais, tais como a Organização dos Estados Americanos - OEA -, tem desempenhado relevante papel no reconhecimento e na implementação dos Direitos Humanos. No âmbito da OEA, muitos instrumentos jurídicos a versarem sobre os Direitos Humanos, tanto convencionais - "hard law" - como de outras naturezas, têm sido produzidos pelos múltiplos órgãos do Organismo regional. Vários deles tratam do direito à segurança pública, que é adotado neste trabalho a título exemplificativo para avaliar a atuação do Sistema Interamericano de Proteção dos Direitos Humanos - SIPDH. O presente estudo objetiva apresentar a estrutura burocrática da OEA, fazer breve escorço sobre sua atuação em relação aos Direitos Humanos, narrar as principais ideias sustentadas por Costas Douzinas em seu livro "O fim dos direitos humanos" e, ao fim, a traçar paralelos entre a realidade empírica da OEA e as reflexões trazidas na obra mencionada. Toda a análise é feita tendo em conta a transversalidade dos Direitos Humanos, em especial da temática concernente à segurança pública. A partir de pesquisas bibliográficas, análise documental e buscasem arquivos dos sítios virtuais da OEA, a vertente análisepretende apresentar, em linhas gerais, os fundamentos que embasam o atuar da Entidade no campo da segurança pública, de modo a concluir se o fim dos Direitos Humanos faz sentido à luz da realidade do SIPDH, compreendendo este último a Comissão Interamericana dos Direitos Humanos CIDH - e a Corte Interamericana dos Direitos Humanos - Corte.Conclui-se que não se pode falar em ocaso dos Direitos Humanos como aponta Douzinas, ao menos no âmbito do Sistema Interamericano.

Palavras - Chave: Direitos Humanos; Organização dos Estados Americanos; Finalidades dos Direitos; Direito Internacional.

\begin{abstract}
The advent of legal international systems, such as found in the Organization of American States, has played a relevant role in the recognition and implementation of human rights. Within the OAS, many legal instruments, as they relate to human rights, both conventional - hard law- instruments, as well as other types have been produced by multiple agencies of the OAS. Several of them deal with the right of public security, which will be shown in this paper as examples to evaluate the performance of the Inter-American Human
\end{abstract}


Rights System- IAHRS. This study aims to present the bureaucratic structure of the OAS, to briefly explain its performance in relation to human rights, to point out the main ideas supported by Costas Douzinas in his book " The End of Human Rights", and finally to draw parallels between the empirical reality of the OAS and Douzinas' reflections. The analysis takes into account the multi-faceted subject of human rights, especially regarding the issue of public security. Searching literature, performing document analysis, and searching virtual OAS sites, enabled this analysis to show, in general, the fundamentals that underpin the work of the OAS in the field of public safety, in order to ascertain whether "The End of Human Rights" makes sense in light of the reality of IAHRS, the latter comprising the Inter-American Commission on Human Rights and the Inter-American Court of Human Rights.

Keywords: Human Rights; Organization of American States; Purposes of rights; International laws.

\section{INTRODUÇÃO}

O objeto do vertente trabalho é analisar a crítica à retórica dos Direitos Humanos, feita pelo professor Costas Douzinas, anunciada no seu livro intitulado "O Fim dos direitos humanos", à luz do Sistema de proteção aos direitos humanos da Organização dos Estados Americanos, tomando-se como referência sua atuação na área de segurança pública.

Desde o fim da Segunda Guerra Mundial, o Direito Internacional dos Direitos Humanos, talvez a mais veemente resposta às atrocidades cometidas em tal conflito transnacional, e a criação de blocos regionais e internacionais tornaram-se temas centrais dos tratados internacionais.

Em razão disso, tem-se passado em revista a noção tradicional de soberania absoluta do Estado, que passa a sofrer um processo de relativização. Intervenções no plano nacional em prol da proteção dos Direitos Humanos e da cooperação entre países estão, cada vez mais, sendo admitidas, tais como a monitoração e responsabilização internacional de países.

Nesse mesmo caminhar, consolidou-se o Sistema normativo global de proteção dos Direitos Humanos, no âmbito das Nações Unidas, que é formado por instrumentos de alcance geral, como os Pactos Internacionais de Direitos Civis e Políticos e de Direitos Econômicos, Sociais e Culturais de 1966, e de alcance específico, como as Convenções internacionais que buscam fazer frente a violações de Direitos Humanos específicos, como a discriminação contra as mulheres, a violação dos direitos das crianças, etc.

Tais instrumentos jurídicos internacionais podem prever a figura de novos direitos, ainda não consagrados no plano interno dos Estados. Em caso de o direito interno já albergar tais direitos, os tratados internacionais de Direitos Humanos terão a função de integrar, complementar e estender a declaração interna de direitos. (AGUADO, 2008, pág. 311)

Formaram-se, também, os não menos importantes sistemas normativos regionais de proteção, visando internacionalizar os Direitos Humanosno plano regional, tal como se dá nas Américas por intermédio da Organização dos Estados Americanos - OEA -, cujos objetivos são a promoção de uma ordem de paz e justiça, de solidariedade e de defesa das soberanias, da integridade territorial e da independência dos povos.

A Organização tem produzido diversos documentos a respeito dos Direitos Humanos, destacando-se, entre outros, a Carta da OEA, a Declaração Americana dos Direitos e Deveres do Homem e a Convenção Americana de Direitos Humanos.

A Carta da Organização dos Estados Americanos, nada obstante tenha se dedicado primordialmente a definir e estabelecer a organização internacional, proclamou o respeito aos 
Direitos Humanos como vetor de atuação da cada Estado e do Organismo Internacional, o que se pode depreender do contido nos seus artigos $3^{\circ}$, "l", 17, 95, "c", 3), e 106. Os outros doisTratados mencionados têm como tema central a consagração de Direitos Humanos no âmbito do continente americano, de modo que, por ora, maiores digressões sobre seu teor não são indispensáveis.

Portanto, não restam dúvidas de que os Direitos Humanos, em especial no âmbito da OEA, se tornaram tema da alta relevância no âmbito internacional, irradiando efeitos contundentes nas legislações e atos internos dos Estados até então cabalmente soberanos.

À luz deste pano de fundo, oportuno comentar a crítica à retórica dos Direitos Humanos, da lavra do professor Costas Douzinas, anunciada no seu livro intitulado "O Fim dos direitos humanos".

Segundo aobra, os Direitos Humanos só têm paradoxos a oferecer.(DOUZINAS, 2009,

O primeiro seria a pouco provável característica de que os direitos humanos abarcariam todas as diferentes perspectivas políticas, religiosas e culturais, o que vai de encontro à realidade de que as diferentes visões de mundo não teriam sido extintas pela aceitação por parte dos mais diversos setores da sociedade da ideia dos Direitos Humanos.

Ulterior paradoxo é o fato deo Século XX ter sido aquele que assinalou a vitória dos Direitos Humanos e, ao mesmo tempo,e que testemunhou as suas maiores violações. (DOUZINAS, 2009, p. 20)Mas não é apenas este cenário desolador o responsável pela afirmação de que os direitos humanos estariam mortos.Por fim, afirma o autor que os direitos humanos não têm se colocado como verdadeira barreira à execução do neoliberalismo globalizado, que está a oprimir os povos pobres, aumentando a distância entre estes e os mais ricos, além de violar bens ambientais e sociais.

Tendo em vista a multidão de áreas em que atua o SIPDH, este artigo tomará como material para avaliação empírica das críticas formuladas pelo autor supracitado apenas a atuação daquele em relação à temática da segurança pública, assunto polêmico acerca do qual se digladiam forças conservadoras e progressistas.

Assim, o presente estudo se ocupará, num primeiro momento, em narrar a estrutura da OEA, para em seguida abordar os tratados internacionais e demais atos, da sua lavra, que disciplinam de alguma maneira Direitos Humanos ligados à segurança pública. Por fim, serão alinhavadas as principais reflexões do autor no tocante aos Direitos Humanos e serão traçados comparativos acerca da atuação do SIPDH e as ideias proclamadas no mencionado livro.

\section{A ATUAÇÃO DA OEA}

Neste capítulo, serão traçados apontamentos sobre a estrutura da OEA, com especial ênfase ao Sistema Interamericano, formado pela Comissão e Corte Interamericanas, bem como a respeito dos tratados internacionais vigentes na Organização regional.

\subsection{ESTRUTURA DA OEA}

De plano, há que se explicar sucintamente como se deu a implementação do Sistema Regional de Proteção dos Direitos Humanos - SRPDH - no continente americano, que nasceu 
com a criação da OEA, bem como de que maneira funciona a Entidade, em sua estrutura burocrática.

No mesmo período da criação da ONU, em 1945, a necessidade da proteção dos direitos fundamentais dos indivíduos em nível supranacional, após a Segunda Guerra Mundial, deu azo à criação de sistemas regionais de proteção aos Direitos Humanos, cujos mecanismos de proteção se revelam mais eficazes em relação àqueles do sistema global, tendo em vista a maior homogeneidade dos países participantes.

Os sistemas regionais de proteção aos Direitos Humanos são os atuais organismos internacionais regionais existentes nos diversos continentes, como no europeu, representado pela Corte Européia de Direitos Humanos; no americano, representado pela Comissão Interamericana e pela Corte Interamericana de Direitos Humanos da Organização dos Estados Americanos; e no africano, representado pela Comissão Africana de Direitos Humanos e dos Povos.

O SRPDH tem como seu marco inicial a Declaração Americana de Direitos e Deveres do Homem - DADDH - , aprovada em abril de 1948, sendo anterior, até mesmo, à Declaração Universal dos Direitos Humanos - DUDH -, datada de dezembro do mesmo ano. Há direitos previstos na DADDH que não estão inscritos naDUDH: direito à previdência, acesso à justiça, direito de petição, proibição da prisão civil por dívida, celeridade da justiça, proibição de instituir tribunais de exceção. De acordo com o Documento, o SRPDH deveria ser posteriormente fortalecido, na medida do possível com a elaboração de tratados com força vinculante obrigatória, quando as circunstâncias fossem mais propícias. À época, foi elaborada para funcionar como mera carta de intenções, sem valor vinculante, tendo, à frente, se constituído em verdadeiro marco para a produção de futuros tratados regionais sobre Direitos Humanos, bem como tendo sido reconhecida por órgãos de proteção de Direitos Humanoscomo detentora de efeitos vinculantes. Porém, foi o Protocolo de Buenos Aires, em 1970, instrumento jurídico vinculante, que absorveu expressamente os conteúdos contidos na DADDH e na Carta, dotando-os de valor normativo.

O SIPDH é composto pela CIDH e pela Corte Interamericana de Direitos HumanosCorte -, ambos órgãos da OEA com atribuições fixadas pela Parte II da Convenção Americana de Direitos Humanos.

Os órgãos têm a função desupervisionar o cumprimento pelos Estados-membros da OEA das obrigações assumidas com a assinatura da Convenção.

A sede da CIDH situa-se em Washington, EUA, mesmo local onde se situa a OEA. É composto o Orgão por 7 (sete) membros eleitos a título pessoal, mas vindos de países membros da OEA, com os quais não guardam vínculos durante a atuação, visto que não são representantes de seus países de origem, restringindo suas função à garantir a observância dos Direitos Humanos pelos Estados-Membros. Os integrantes são escolhidos pela AssembleiaGeral da OEA, para mandato de quatro anos, prorrogável pelo mesmo período.(OEA, 2011)

A competência primordial da $\mathrm{CIDH}$ se divide, em rápidas palavras, em duas: a) o recebimento de petições individuais, dando contada violação a algum dos artigos da Convenção Americana sobre Direitos Humanos ou de outros tratados de alcance regional; b) efeitura de relatórios sobre os Direitos Humanos no continente, os quais podem se limitar a um tema ou região específicos.

No que toca aos relatórios, é possível à CIDH emitir relatórios anuais sobre a situação dos Direitos Humanos, periodicamente levados à Assembleia-Geral da OEA. 
Também, a CIDH detém, entre suas faculdades, o poder de realizar visitas "in loco", quando julgar indispensável que um de seus membros faça pessoalmente uma verificação de condições a ela relatadas, ou, ainda, para fazer uma missão de verificação geral.

No art. 41 da Convenção consta o rol de competências do órgão.

No tocante à primeira função da Comissão, de receber as denúncias individuais de violações perpetradas por Estados-Partes da OEA, a legitimidade ativa dos denunciantes é bastante vasta, de modo que qualquer pessoa ou grupo de pessoas, ou ainda entidades não governamentais legalmente constituídas pode levar um caso a Comissão. Não se faz imprescindível comprovar liame específico coma violação ou ser vítima para levar uma denúncia ao órgão. A Comissão é competente para receber casos de violação perpetrados por Estados Membros da OEA que ratificaram ou não a Convenção Americana. O Protocolo de Buenos Aires, como referido acima, concedeu à Comissão poderes para dar seguimento a denúncias de violações à Carta da OEA ou à Declaração Americana, agora documentos com juridicidade.

A Comissão não possui competência para emitir sentenças e resolver de modo definitivo os conflitos a ela submetidos. Ao se deparar com violações a direitos garantidos no âmbito da OEA, a Comissão redige um Relatório Final com recomendações ao Estado, visando a retornar ao estado anterior ao ilícito, ou cessar imediatamente a violação e reparar/indenizar o ofendido por todos os prejuízos sofridos, ou ainda, nas palavras da Convenção, "determina que se assegure ao prejudicado o gozo do seu direito ou liberdade violados”. (GONZAGA, 2005)

Considerando a importância das funções que a CIDH exerce, não é demasiado afirmar que se trata do "Ministério Público" do SIDH, "pela independência com que atua, por possuir legitimidade para agir perante a Corte IDH e também por ser chamada a intervir em todos os casos em trâmite perante esse órgão, na qualidade de órgão de representação de todos os membros da OEA".

O órgão jurisdicional do SIPDH é a Corte. Seus membros são designados juízes, que proferem sentenças de modo definitivo e inapelável, tudo nos termos do Pacto de São José da Costa Rica. Ademais, suas decisões são vinculantes, de modo que os Estados Membros que se comprometeram a respeitar sua jurisdição não podem se recusar a cumpri-las.

Diversamente do que ocorre com a CIDH, em que as atribuições são efeito automático da aprovação do ou adesão à Convenção, para que a Corte tenha competência jurisdicional sobre determinado país, faz-se necessário que este aceite a função contenciosa do órgão, com manifestação de vontade expressa nesse sentido, a ser depositada na sede da OEA. O Brasil, embora tenha adotado - ratificado - a Convenção em 1992, e, portanto, por consectário legal tenha se sujeitado ao monitoramento pela Comissão Interamericana, apenas permitiu ser jurisdicionado pela Corte em dezembro de 1998.

A sentença da lavra da Corte, nos dizeres da Convenção, deve ser executada no plano interno como se produzida pelo direito interno.

Ao lado da função jurisdicional e contenciosa, a Corte emite os denominados Pareceres Consultivos, frutos da função hermenêutica do órgão, ocasiões em que torna pública e obrigatória a sua interpretação concernente a dispositivos previstos nos tratados regionais de Direitos Humanos, definindo sentido e alcance das normas em questão, até mesmo à luz da legislação nacional - controle de convencionalidade. Tratados internacionais do SIPDH.

Considerando que o presente estudo objetiva fazer uma análise ligeira da atuação do SIPDH à luz das reflexões formuladas por Costas Douzinas, no seu livro "O fim dos direitos 
humanos", optou-se por delimitar a exposição dos atos do Organismo regional ao tema segurança pública. Portanto, apenas serão relatados os atos relacionados aos Direitos Humanos sob o viés da segurança pública.

De plano, é interessante pontuar que o SIPDHapresenta clara opção pela conceituação da segurança pública com a qual desenvolve seus trabalhos.

Durante a Conferência Especial sobre Segurança, ocorrida em 28 de outubro de 2003, integrada por Ministros das Relações Exteriores dos países Membros da OEA (MINISTÉRIO DAS RELAÇÕES EXTERIORES, 2003), perfilhou-se nova definição de segurança pública, tendo sido, na ocasião, entendido que a

\begin{abstract}
segurança no Hemisfério é de alcance multidimensional, inclui as ameaças tradicionais e as novas ameaças, preocupações e outros desafios à segurança dos Estados do Hemisfério, incorpora as prioridades de cada Estado, contribui para a consolidação da paz, para o desenvolvimento integral e para a justiça social e baseiase em valores democráticos, no respeito, promoção e defesa dos direitos humanos, na solidariedade, na cooperação e no respeito à soberania nacional. (OEA, 2003)
\end{abstract}

Também, reconheceu-se que "a paz é um valor e um princípio em si e baseia-se na democracia, respeito aos Direitos Humanos, solidariedade e respeito ao Direito Internacional", de modo que a (OEA, 2003) “[...]arquitetura de segurança contribuirá para preservá-la por meio do fortalecimento dos mecanismos de cooperação entre os Estados”.

Afirmou-se, ainda, que o motivo principal da segurança é a proteção da pessoa humana, queé fortalecida quando se aprofunda a consideração pela dimensão humana e as

condições de segurança humana melhoram mediante o pleno respeito da dignidade, dos direitos humanos e das liberdades fundamentais das pessoas, bem como mediante a promoção do desenvolvimento econômico e social, a inclusão social e a educação e o combate à pobreza, às enfermidades e à fome. (OEA, 2003)

Em 2011, a Declaração de San Salvador sobre Segurança Pública nas Américas progrediu na reformulação conceitual de segurança iniciada em 2003. Reconheceu que o crime, a violência e a insegurança afetam negativamente o desenvolvimento social, econômico e político das sociedades e violam os Direitos Humanos do indivíduo, centro da segurança pública, devendo os Estados implementar políticas de longo prazo em matéria de prevenção, aplicação da lei e reabilitação e reinserção social, a fim de assegurar um enfoque integral, com especial ênfase ao enfrentamento das causas do crime e à satisfação das necessidades dos grupos vulneráveis, em um quadro de proteção e promoção dos Direitos Humanos. Em virtude do caráter multicausal da violência, reconhecido na ocasião, mais uma vez tais políticas devem envolver múltiplos atores, tais como o indivíduo, os governos em todos os níveis, a sociedade civil, as comunidades, os meios de comunicação e o setor privado e acadêmico. (OEA, 2011)

Assim, a outra concepção, que visualizava segurança pública pelas lentes da hostilidade, da guerra e do autoritarismo, decerto não restou adotada, prevalecendo a opinião segundo o qual segurança pública é um direito, de todos, e simultaneamente um dever do Estado, configurando-se em serviço público a encargo deste, de modo que inexistem inimigos, despidos de qualquer direito e garantia, a serem combatidos previamente. (OEA, 2011) 
Indo adiante, cumpre delinear breve relato sobre os demais tratados internacionais que de algum modo cuidam do tema segurança pública no âmbito interamericano.

Em 12 de fevereiro de 1969, os países componentes da OEA aprovaram a Convenção Interamericana de Direitos Humanos, um tratado multilateral, com força jurídica internacional, apelidadode Pacto de São José da Costa Rica, visto que a conferência que o criou se realizou naquele País.

A Convenção sópassou a vigorar em 1978, por ocasião da ratificação do décimo primeiro país, tendo como seu objetivo primordial a instituição de órgãos com competência para supervisionar a atuação dos países integrantes em relação aos Direitos Humanos.

O Brasil, a seu turno, apenas ratificou o Tratado em 1992, muito tempo após a sua entrada em vigor, o que só ocorreu após a sua redemocratização.

A partir de então muitos outros Tratados de efeito vinculante - convenções, pactos e protocolos -, a versarem sobre Direitos Humanos em nível regional, passaram a ser discutidos e aprovados pela OEA, iniciando esta nova fase pela Convenção Americana dos Direitos Humanos - CADH -, de 1969, que pela sua importância será objeto de tópico especial e que, como já visto, consagrou que "toda pessoa tem direito à liberdade e à segurança pessoais".

Em diversos outros pontos, há destaque para a segurança pública, como circunstância a temperar os demais Direitos Humanos, o que pode ser visualizado nos artigos 12, 3; 13, 2, b); 15; 16, 2; e 22, 3. Por fim, o artigo 32, 2, da CADH, ao tratar dos deveres dos cidadãos, define que "os direitos de cada pessoa são limitados pelos direitos dos demais, pela segurança de todos e pelas justas exigências do bem comum, em uma sociedade democrática".

Nada obstante o conteúdo da Convenção, até alguns anos atrás o objeto da pauta do Direito Internacional nas Américas, relacionado à segurança, dizia respeito exclusivamente à defesa dos Estados contra ataques estrangeiros ou, no máximo, de grupos internos insurgentes.

Todavia, em recente período, outras ameaças passaram a constar na agenda da segurança pública da OEA, que trouxeram à baila problemas antes exclusivos do plano interno de cada país e que, devido ao fenômeno da globalização, cada vez mais acentuada, atualmente interferem no plano regional e mundial, tais como o problema das drogas, da violência urbana, do tráfico de pessoas, das organizações criminosas, da corrupção, dos atentados cibernéticos, etc.

Portanto, Tratados veiculando diferentes manifestações dos Direitos Humanos, no tocante à segurança pública, passaram a estar na ordem do dia da OEA.

Em 1985, adotou-se a Convenção Interamericana para Prevenir e Punir a Tortura, definindo os atos de tortura, a serem sempre responsabilizados, mediante investigação e persecução penal adequada, mesmo quando o autor alegue agir em obediência a ordens superiores.

Outro instrumento legal de grande relevo, no que concerne à segurança pública, é a Convenção Interamericana para Prevenir, Punir e Erradicar a Violência Contra a Mulher Convenção de Belém do Pará -, deliberada pela Assembleia-Geral da OEA em 1994. Constitui-se no marco histórico internacional na perspectiva de coibir a violência contra a mulher, além de ter funcionado como fundamento para a aprovação, no plano interno, da Lei Maria de Penha.

A despeito de não tratar sobre o tema segurança pública, em sua acepção tradicional, é inegável a relevância da Convenção Interamericana Contra a Corrupção, adotada em 1996, no que se refere à eficácia das implementações das políticas públicas de segurança pública. 
Em 1997, celebrou-se a Convenção Interamericana para o Controle da Fabricação e do Tráfico ilícito de Armas de Fogo, Munições e Explosivos, bem assim se previu a cooperação internacional nesse âmbito.

\subsection{DEMAIS ATOS DA OEA SOBRE DIREITO À SEGURANÇA PÚBLICA}

No dia 30 de abril de 1948, durante a IX Conferência Internacional Americana, realizada em Bogotá, foi aprovada a Carta da Organização dos Estados Americanos - COEA -, criando a Organização da qual fazem parte todos os 35 Estados das Américas do Norte, Central e do Sul.

Na COEA, redigida na Conferência citada, definiram-se expressamente os Direitos Humanos entre os princípios sobre os quais se fundamentava a Organização. É muito importante pontuar que a defesa dos Direitos Humanos e dos demais interesses da comunidade de nações integrantes no âmbito da OEA é autônoma ao SIPDH, de modo que funciona independentemente de terem os Estados-membros da OEA subscrito a Convenção e se submetido à jurisdição da Corte Interamericana dos Direitos Humanos. Contudo, em muitos momentos e assuntos, os temas trabalhados na OEA serão conexos ou idênticos aos tratados no SIPDH, mesmo porque, como visto, a OEA também se encarregou de zelar, ainda que de modo lateral, pelos Direitos Humanos.

A OEA realiza suas funções por intermédio de vários órgãos.Alguns destes - exceto a Comissão Interamericana e a Corte Interamericana, que serão tratadas em capítulos à parte -, por guardarempertinência com o tema em debate, serão mencionados a seguir.

A Assembleia-Geral é o órgão supremo que define a ação e a política gerais da Organização, sendo convocada anualmente em sessão regular, podendo haver sessões especiais. Em suas reuniões cada um dos Estados Membrospossui um voto.

O Conselho Permanente da Organização, vinculado diretamente à Assembleia Geral, tem sua competência fixada pela Carta e por outros instrumentos interamericanos, bem como as funções delegadas pela Assembleia Geral e pela Reunião de Consulta dos Ministros das Relações Exteriores. Em suma, o órgão tem por objetivos zelar pela manutenção das relações de amizade entre os Estados-membros, executar as decisões da Assembleia Geral ou da Reunião de Consulta dos Ministros das Relações Exteriores, cujo cumprimento não tenha sido atribuído a nenhuma outra entidade e coordenar seus órgãos subsidiários, organismos e comissões.

Em setembro de 2007, o Secretário-Geral da OEA convocou a Comissão de Segurança Hemisférica do Conselho Permanente da OEA, para que verificasse a necessidade de arbitrar medidas aos Governos das Américas para enfrentar o crescente problema da violência no continente, com a adoção de políticas públicas adequadas, eficientes e coordenadas entre todos países. O conselho Permanente da OEA, em resposta, convocou reunião entre os Ministros de Segurança de todos os Governos locais, constituindo, assim, novo foro interamericano, de cariz técnico e político, a respeito dos temas concernentes à segurança pública, para coordenar ações nos campos das políticas públicas, da informação, da comunicação, da tecnologia, da capacitação e em todos os necessários para obter êxito na tarefa de combater coletivamente o crime e a violência na região.

A Secretaria-Geral, órgão central e permanente da Organização, com sede em Washington, d.C, detém atribuições que estão delineadas a partir do art. 107 da Carta da OEA. No tocante à segurança pública, a Secretaria-Geral, com apoio dos Estados Membros, tem promovido nos últimos anos a construção e consolidação de uma arquitetura institucional, 
cujo órgão político principal é a Reunião de Ministros em Matéria de Segurança Pública das Américas - MISPA-, órgão a que se fez referência acima, instituído a partir da iniciativa do Secretário-Geral e Conselho Permanente da OEA. O objetivo destes encontros é fortalecer o diálogo entre os atores chaves na matéria, com vistas a lograr uma cooperação efetiva, facilitar a transferência de conhecimentos, apoiar a assistência técnica e o intercâmbio de práticas exitosas neste âmbito(OEA, 2014).

Ainda no bojo da Secretaria-Geral da OEA,encontra-se a Secretaria de Segurança Multidimensional - SMS -, criada em 2005, cuja missão é promover e coordenar a cooperação entre os Estados-membros da OEA com o SIPDH e outros organismos do Sistema Internacional para avaliar, prevenir, enfrentar e responder eficazmente às ameaças à segurança, com vista a ser a principal referência do Hemisfério para ampliar a cooperação e reforçar as capacidades dos Estados membros da OEA. O escopo de atividades da SMS é determinado pela Declaração sobre Segurança nas Américas, aprovada em outubro de 2003, acima mencionada.

A SMS é composta pelo Escritório Executivo do Secretário de Segurança Multidimensional e pelas seguintes dependências: a) Secretaria Executiva da Comissão Interamericana para o Controle do Abuso de Drogas; b) Secretaria do Comitê Interamericano contra o Terrorismo, e c) Departamento de Segurança Pública - DSP. Muito embora as duas primeiras Secretarias ostentem atribuições sobre temas por demais próximos à segurança pública, é o Departamento de Segurança Pública - DSP - o órgão responsável por coordenar a cooperação e a criação de políticas públicas, no âmbito da OEA, em relação aos Estados Membros, como o Brasil, de modo que será tal Departamento objeto de análise de agora em diante.

O DSP integra a SMS da OEA e foi criado para desenhar e implementar estratégias orientadas a apoiar os esforços dos Estados-membros para fazer frente às ameaças - novas e tradicionais - da segurança pública, sempre considerando o respeito devido aos Direitos Humanos.

Outra relevante empresa do DPS é a elaboração de livros contendo compilações dos Documentos-chave da OEA sobre Segurança - "Documentos Claves de la OEA sobre Seguridad"-,ainda não disponíveis em português, apenas em espanhol e inglês. Trata-se de uma série de declarações, convenções e outros documentos da OEA, relacionados com temas de segurança.Destacam-se os seguintes documentos: a)"La Seguridad Pública em las Américas: Retos e Oportunidades, relatório que traça um panorama geral e institucional acerca da situação da segurança pública nas Américas e aborda a prevenção da insegurança, os princípios das políticas públicas de segurança, apresentando, ao fim, algumas sugestões para amenizar o problema; b) "La Cárcel: problemas y desafios para las Américas"; ec) "Violencia sexual em Latinoamérica y El Caribe: Análisis de datos secundários".

Ainda, como referido acima, mostra-se órgão importante para o diálogo entre os países das Américas a Reunião de Ministros em Matéria de Segurança Pública das Américas.

Nos dias 7 e 8 de outubro de 2008, aconteceu a Primeira Reunião de Ministros responsáveis pela Segurança Pública, em que se adotou o "Compromisso pela Segurança Pública" e se reconheceu que a segurança pública é dever e obrigação exclusiva do Estado, fortalece o estado de direito e tem como fim salvaguardar a integridade e segurança das pessoas e proteger o gozo de todos os demais direitos, bem como as condições de segurança pública melhoram mediante o respeito por todos os Direitos Humanos e as liberdades fundamentais, assim como mediante a promoção da educação, da saúde e do desenvolvimento econômico e social. Também, o cumprimento das leis como parte de qualquer estratégia de segurança pública, notadamente o direito internacional na cultura institucional, na formação,

Revista de Direito Brasileira | São Paulo, SP | v. 13 | n. 6 | p. 213 - 230 | jan./abr. 2016 
no treinamento e na atuação das forças de segurança, restou admitido como fator importante para a redução da criminalidade.

Por fim, mencione-se o não menos interessante órgão gerado pelo DPS da Secretaria Multidimensional da OEA, denominado Observatório de Segurança, cuja finalidade é reunir, sistematizar e analisar a informação criminal relevante no nível hemisférico, produzida pelos países e por outras pessoas interessadas, com a finalidade de servir como instrumento a ser utilizado pelo controle social, de modo a permitir maior fiscalização e participação democrática da sociedade civil no tema.

Em relação à atuação da Comissão Interamericana dos Direitos Humanos - CIDH -, vale citar as seguintes iniciativas.

Por intermédio da Resolução $\mathrm{n}^{\circ}$ 01/2008, a CIDH aprovou, à unanimidade, o documento "Princípios e Boas Práticas sobre a Proteção das Pessoas Privadas de Liberdade nas Américas". O processo de elaboração de tais princípios teve começo em 2005, no âmbito da CIPDH, mais precisamente na Relatoria sobre os Direitos das Pessoas Privadas de Liberdade nas Américas. O processo de elaboração da publicação contou com a colaboração de vários atores, tais como governos dos Estados-membros da OEA, experts, universidades, agências internacionais e organizações não governamentais.

Ainda, vale mencionar o Relatório no 54/2001, da lavra da CIPDH, a corroborar o direito à segurança pública específica, adequada ao perfil da mulher, comumente vítima de violações aos seus direitos em função de seu gênero. Transcreve-se o seguinte trecho do Documento:

"A CVM protege, entre outros, os seguintes direitos da mulher violados pela existência dessa violência: o direito a uma vida livre de violência (artigo 3), a que seja respeitada sua vida, sua integridade física, psíquica e moral e sua segurança pessoal, sua dignidade pessoal e igual proteção perante a lei e da lei; e a recurso simples e rápido perante os tribunais competentes, que a ampare contra atos que violem seus direitos (artigo 4,a,b,c,d,e,f,g e os consequientes deveres do Estado estabelecidos no artigo 7 desse instrumento." (OEA, 2011)

À derradeira, registre-se que a CIDH emitiu Relatório sobre Segurança Pública e Direitos Humanos, no ano de 2009, em cujo documento se reiteraram as obrigações dos Estados Membros com a segurança pública, que deve ser atendida mediante políticas públicas integrais e de longo prazo, notadamente em respeito aos Direitos Humanos em face da violência e criminalidade, com especial ênfase à prevenção destes fenômenos.

Sobre a atuação da Corte Interamerica, serão apresentados as seguintes ações.

O primeiro caso a ser lembrado neste artigo é o alusivo ao "Caso de las Masacres de Tuango VS. Colômbia”, sentenciado em julho de 2006, em cujo julgamento a Corte, fazendo leitura do Pacto de São José da Costa Rica, estabeleceu que o Estado há que garantir a segurança dos habitantes do município de Ituango que lá desejem habitar novamente, em face de possíveis ameaças vindas de grupos paramilitares - particulares - possivelmente responsáveis pelos atentados objeto do julgado. Ressaltaram os Juízes da Corte que, em caso de inexistirem condições para tanto, de modo supletivo, deve o Estado dispor dos recursos necessário para que as vítimas possam se reassentar em condições similares às que antes se encontravam, em locais livremente por elas indicados. (OEA, 2006)

Em 23 de outubro de 2012, no julgamento do Caso Gutiérrez Soler, além de reafirmar sua jurisprudência iterativa de que o Estado deve fornecer meios para garantir a segurança de vítimas de atentado aos Direitos Humanos, estabeleceu que os Estados respondem pelos atos de seus agentes, realizados ao amparo de seu caráter oficial, ou não, ainda que atuem fora dos limites de sua competência ou em violação ao direito interno. Assim, tem o dever de bem 
vigiar que o seus corpos de segurança, para quem é atribuído o direito de uso da força legítima, respeitem o direito à vida de quem está sob sua jurisdição. Por fim, na mesma assentada, entendeu que o Estado pode valer-se de prisão coletiva como mecanismo para garantir a segurança pública do cidadão, contanto que haja elementos para acreditar que a atuação de cada uma das pessoas presas se enquadre em alguma das causas de detenção previstas pelas normas internas e que se mostra consentânea com a Convenção, de modo que existam provas para individualizar e separar as condutas de cada um dos detentos, pelo controle judicial. (OEA, 2012)

Já no caso Garibaldi VS. Brasil, cuja sentença foi prolatada em setembro de 2009, exsurge linha de argumentação a evidenciar que a) a investigação de violações de Direitos Humanos é ao mesmo tempo uma obrigação estatal e um direito das vítimas, b) o Estado tem o dever de garantia em prol dos cidadãos, cujo cumprimento deve se dar pela via da prevenção - segurança pública, por excelência - e pela via da apuração das infrações, o que deve se dar independentemente da vontade das vítimas, e c) a averiguação deve se dar de modo sério, imparcial e efetivo, mediante o uso de todos os instrumentos legais para a determinação da verdade, com observância aos princípios norteadores, especificados pela Corte $^{1}$. Interessa notar que neste caso o Estado brasileiro foi responsabilizado por ato de particulares - homicídio -, que não se apurou corretamente, de modo que restou inequívoco que o Estado tem o dever de garantir a segurança dos seus jurisdicionados, até mesmo ficando compelido a adotar medidas eficazes para evitar a proliferação de grupos criminosos e violentos, as quais estão além da disposição de apenas expedir e implementar medidas de caráter legislativo, de maneira que a efetividade dos direitos e liberdades, previstos na Convenção deve ser elevada por ações concretas.

Outrossim, merece ser transcrito trecho da sentença o Caso Ximenes Lopes VS. Brasil, em que o dever de o Estado garantir a segurança pública é realçado (OEA, 2006):

\begin{abstract}
Aquele que atua como garante de algo ou de alguém, ou seja, aquele que assume a função de garantir a proteção de certos bens a favor de determinadas pessoas, assume o dever de oferecer cuidados a esses bens e pessoas, compatíveis com a tarefa que assume, proveniente da lei, de um acordo de vontades ou de outras fontes do dever de garantia. O Estado é garante, em geral, dos que se acham sob sua jurisdição. O dever de cuidado que lhe cabe transita, conforme as circunstâncias, pelas mais diversassituações: desde a garantia geral de paz e segurança, até o preciso dever de cuidado que a ele concerne no manejo de serviços públicos de primeira ordem e na atenção a sujeitos que não possam valer-se por si mesmos ou tenham severamente limitada sua capacidade de fazê-lo. O dever de cuidado do Estado garante varia, pois, em qualidade e intensidade, conforme as características do bem garantido e dos titulares desse bem. Nesta ordem, dificilmente poderia haver maior exigência que a que se apresenta na prestação de serviços médicos, matéria da sentença a que anexo este Voto.
\end{abstract}

A título de ilustração, recorde-se da decisão do caso "Montero Arangureny outros (Retén de Catia) Vs. Venezuela" (OEA, 2006). Na ocasião a Corte assentou, como fundamento de sua decisão, que a utilização de forças militares para o desenvolvimento de tarefas policiais pode ocasionar muitos problemas, visto que tais intervenções podemgerar violações aos Direitos Humanos, visto que tais corporações fogem ao controle do aparato civil - justiça e controle administrativo.

\title{
2. APONTAMENTOS SOBRE O LIVRO "O FIM DOS DIREITOS HUMANOS"
}

Segundo Costas Douzinas, mormente nos últimos 30 anos, o discurso dos Direitos Humanos tem triunfado, logrando, de modo inédito, unir a direita e esquerda, o norte e o sul, a 
igreja e o estado, bem como prometendo o pleno cumprimento dos princípios do Iluminismo e o fim das disputas ideológicas. (DOUZINAS, 2009, p. 19)

Todavia, o autor entende que os Direitos Humanos têm a oferecer apenas paradoxos e não soluções aos problemas a serem enfrentados pela humanidade.

Um primeiro paradoxo é o fato de que,no século $\mathrm{XX}$ e nos dias atuais, tem-se testemunhado as maiores violações aos Direitos Humanos, nada obstante todos os solenes tratados internacionais e declarações a versarem sobre o tema.Mesmo após a adoção de muitos instrumentos internacionais a tratarem dos Direitos Humanos, não foram inúmeros os massacres, osgenocídios, as faxinas étnicas e o Holocausto, presenciados pela humanidade. Além disso, em nenhum outro período adistancia entre pobres e ricos foi tão grande, além de que nunca tantas pessoas foram subjugadas epassaram fome (DOUZINAS, 2009, p. 20).

Daí por que, segundo Costas Douzinas, a crença, principalmente por parte dos atuais diplomatas e juristas internacionais, na eficácia e efetividade dos Direitos Humanos seria equivalente à adoração a entes metafísicos, de modo que inexistiria insulto maior às vítimas de catástrofes naturais ou produzidas pelo homem, de fome coletiva e guerra, de terremotos e faxina étnica, de epidemia e tortura, que lhes dizer que, de acordo com um importante tratado internacional, elas têm direito à comida e a paz, a um abrigo e a um lar ou a atendimento médico e a um fim aos maus-tratos.

O segundo problema a acarretar o fim dos Direitos Humanos seria o de que as disposições sobre eles são sempre gerais e abstratas.

Toma o autor como exemplo o direito à vida, que abre a maioria das constituições e tratados de Direitos Humanos, o qual se trataria de mera afirmação e, por consectário lógico, não responderia a perguntas sobre o aborto, a pena de morte, aeutanásia, ou mesmo se esse direito protege ospré-requisitos necessários à sobrevivência,como comida, abrigo ou segurosaúde. Para o professor, namaioria dos casos, uma reivindicação de direitoshumanos é o princípio e não o fim de umadisputa sobre o significado do direito ou suaposição relativa em relação a outros direitosconflitantes. Assim, considerações de ordem moral, política ou ideológica têm que ser manejadas na argumentação jurídica, ao menos de modo indireto. Portanto, as decisões sobre os Direitos Humanos dependem inequivocamente do posicionamento ideológico dos julgadores.

Diante dessas características, o discurso de que todos são livres e iguais é falso e encobre a realidade social, que sempre demanda lutas políticas para a implementação dos direitos, até mesmo dos já proclamados em documentos internacionais. Segundo o professor, os detentores do poder mostram os Direitos Humanos como neutros politicamente, o que acaba por viciá-los e retirar-lhes a capacidade de servirem como instrumento de mudança social.

A origem e destino de uma declaração de Direitos estão sempre imersos em conflito e aporias. Douzinas sustenta o caráter prospectivo e indeterminado dos Direitos Humanos, fazendo de suas proclamações um modelo de "indecibilidade".(DOUZINAS, 2009, p. 42)

Daí adviria a possibilidade de o discurso dos Direitos Humanos, de modo indevido, esvaziar a luta e o debate político, trazendo apenas argumentação jurídica à baila, utilizada somente por burocratas conservadores - governos, instituições internacionais, juristas e diplomatas -, e não por instituições democráticas progressistas, que permite que o discurso dos Direitos Humanos seja cooptado pelo poder público eprivado.

Segundo o autor,foi Karl Marx o primeiro a enfatizar o caráter histórico dos direitos humanos em oposição às prerrogativas inalienáveis, naturais e universais dos direitos. Depois da reflexão de Marx, ficou claro que os Direitos Humanos são criações da modernidade, 
construções sociais e legais,instrumentos limitados e limitadores do Direito, o produto da política do seu tempo e, por fim, o fruto da razão do capital e não da razão pública da sociedade.

Por isso, a finalidade dos Direitos Humanos estaria sendo destruída, sobretudo por grandes potências que cooptaram os Direitos Humanos, as quais, agindo sob o pretexto de disseminar a liberdade e a democracia mundo afora, produziram grande sofrimento humano, valendo-se da ambiguidade de tais direitos (DOUZINAS, 2009, p. 15).

Consoante o que sustenta o autor, o fim dos Direitos Humanos é o seu fim utópico, isto é, a visão de um futuro que ainda não chegou e que não vai chegar, mas que provoca todos a prosseguir e a resistir todas as vezes em que há opressão.

Douzinas entende que:

"O fim dos direitos humanos assim como o fim do Direito Natural, é a promessa do
ainda não, da indeterminação da autocriação existencial diante do medo da incerteza
e das certezas inautênticas do presente" (DOUZINAS, 2009, p. 384).

O autor não nega quetornar institucionais os Direitos Humanos seja importante (DOUZINAS, 2009, p. 156), mas alerta ele que muitas vezes a sua merainserção em códigos, tratados e convenções é uma forma de os governos, seus maiores violadores, apaziguarem sua consciência coletiva de maneira pública.

A terceira dificuldade oriunda da evolução do Direito Internacional dos Direitos Humanos seria a banalização e a ampliação desmensurada do catálogo dos Direitos Humanos. Conforme Costas Douzinas, nos últimos tempos estes se tornaram, ao mesmo tempo, o princípioda libertação contra a opressão e dominação, o grito dos sem-teto, dosdespossuídos, e o discurso dos playboys, dos ávidos consumidores eempresários. De modo geral, todos, independentemente da posição socialque ocupam, adotaram a linguagem dos Direitos Humanos.

É por intermédio de uma interpretação psicanalítica dos Direitos Humanos que o autor explica a proliferação e obsessão por mais e mais direitos. É pelo desejo de suprir suas carências- à luz da teoria de Lacan - que os indivíduos continuam demandando e inventando novos direitos, já que a falta nunca é satisfeita. Dessa forma, os Direitos Humanos mantêm a atividade do desejo. Cada sucesso pela conquista de novos direitos leva a necessidade de outras reivindicações, de modo que as demandas nunca serão completamente preenchidas, razão por que tudo o que há se transforma em reivindicação legal - agora, em nível internacional. Nenhum Direito Humano, nestes termos, será totalmente satisfatório. Isso não significa que devem ser rejeitados, mas esclarece que toda reivindicação por mais direitos conterá lacunas. Portanto, o incessanteimperativo de se criar e positivar mais e novos direitos não representa maior proteção e menos violação.

Ainda sobre a vulgarização dos Direitos Humanos, agora utilizados retoricamente pelos seus maiores violadores, o autor esclarece que são os Direitos Humanos, declarados como universais e indivisíveis, uma universalização das prioridades dos Estados ocidentais ricos, o que possibilita uma utilização paradoxal desses direitos. Eles funcionampara as potências dentro dos limites impostos pelos tratados internacionaise seus sistemas de proteção, respeitando sempre a soberania nacional e anão-intervenção nos Estados membros. Por outro lado, quando se trata depaíses "menos influentes", os direitos humanos são tidos como válidos atémesmo contra a soberania nacional e, portanto, justificam intervenções.

\section{A CRÍTICA DE COSTAS DOUZINAS E O SIPDH}

Revista de Direito Brasileira | São Paulo, SP | v. 13 | n. 6 | p. 213 - 230 | jan./abr. 2016 
Tomou-se como parâmetro a atuação da OEA no que toca à segurança pública, para avaliar se a crítica formulada por Costas Douzinas encontra eco no Direito Internacional dos Direitos Humanos desenvolvido na esfera regional. Este tema - segurança pública - é emblemático por ser um dos que mais suscita ferozes debates entre as forças progressistas e as conservadoras, mormente no que toca à compreensão - o modelo - de segurança pública a ser levado a cabo pelos Estados. Como visto, rejeitou-se na OEA a concepção reacionária que visualizava segurança pública pelas lentes da hostilidade, da guerra e do autoritarismo, preponderando acompreensão de que é um direito, de todos, e simultaneamente um dever do Estado, configurando-se em serviço público a encargo deste, de modo que inexistem inimigos, previamente estabelecidos e despidos de qualquer direito e garantia, a serem combatidos. Portanto, optou-se por fazer valer as garantias do cidadão contra os atentados aos Direitos Humanos oriundos dos agentes públicos e particulares, com especial atenção ao enfoque integral da matéria, que passa pelo enfrentamento das causas sociais ensejadoras da criminalidade e pela satisfação das necessidades dos grupos vulneráveis, em um quadro de proteção e promoção dos Direitos Humanos.

Neste primeiro ponto, vê-se que a crítica formulada não merece medrar à luz do SIPDH e seu agir em relação aos Direitos Humanos que giram em torno da segurança pública, os quais estão a cumprir - por óbvio não ainda de modo satisfatório - suas finalidades de ser instrumento de luta contra as opressões.

Os órgãos componentes da OEA têm sido utilizados como instrumento de luta política contra violações, abusos e explorações, entre outros motivos, porque permitem que sejam manejadas demandas,contenciosas ou não, em face dos seus Estados Membros, e que integrantes razoavelmente independentes - não vinculados diretamente a seu Estado Membro - laborem em tais casos e profiram decisões sem vínculos hierárquicos.Assim, tem vigorado o devido processo legal, de modo que decisões arbitrárias, provenientes apenas de um interessado - como aconteceu em guerras em que os Estados Unidos da América iniciou ou em intervenções militares mediadas pela ONU, sem qualquer deliberação por órgãos verdadeiramente democráticos -, geralmente um país rico, beligerante e militarmente preparado, não tem sidoproferidas.

A segurança pública, pois, tem sido defendida pelo viés do cidadão, sobretudo o mais vulnerável e historicamente vitimizado, a partir da tutela de interesses humanos e não do capital.

Sinal eloquente e inequívoco do que se está a sustentar neste capítulo é a não adesão dos Estados mais ricos e próximos ao capital, como os EUA e o Canadá ${ }^{2}$, ao sistema interamericano em comento.

A implementação jurídica dos tratados, que passaram a constar como direitos subjetivos dos cidadãos dos países que aderiram ao sistema não deixaram de constar da pauta dos movimentos sociais. No caso da segurança pública, veja-se os exemplos das campanhas e movimentos articulados e executados sobre temas como desarmamento, violência contra a mulher, corrupção, etc. E a mobilização social tem recrudescido com a atuação da OEA, o que pode ser comprovado pelo Observatório Social da violência pública no continente.

Ademais, tem-se um mecanismo juridicamente estável e igualitário para dirimir as questões, contra qual em tese não prevalece o interesse de um único estado, sobretudo do mais forte econômica e militarmente.

Assim, as críticas reveladas pelo professor, diante da experiência das Américas, não fazem pleno sentido ante o SIPDH. Afirmar que os Estados se submetem a convenções apenas e tão-só para aparentar que respeitam os Direitos Humanos, enquanto em verdade os governos se despem de quaisquer considerações éticas, não se mostra coerente diante da postura e 
esforço de alguns Estados, tais como os integrantes do SRIDH, em implementar e fazer valer direitos. Portanto, a análise sempre negativa do agir estatal nem sempre é o caminho mais adequado a seguir. Todavia, é oportuna a critica, segundo a qual a importância do Direito Internacional dos Direitos Humanos ainda é relativamente diminuta, porquanto depende a sua consecução da cooperação dos Estados soberanos, por meio de suas leis e sistemas de Justiça internos, para a proteção efetiva dos direitos. Assim, carece ainda o SIPDHde melhoras, a fim de tornar-se cada vez mais independente e efetivo.

Outro ponto a não ser esquecido é o reprovação direcionada pelos órgãos da OEA, principalmente pela Corte respectiva, às forças de segurança pública militares, o que vem ao encontro das lutas dos movimentos progressistas e contrários ao uso de práticas recorrentes e em regimes totalitários e ditatoriais.

\section{CONSIDERAÇÕES FINAIS}

A atuação da OEA, por suas mais proeminentes Instituições ou por meio de seus Órgãos secundários, implica relevantes consectários para a efetiva proteção regional dos Direitos Humanos.

À vista do expendido durante o estudo, é fácil observar que é constantemente crescente a integração entre os Membros da OEA no que se refere à segurança pública - tema transversal dos Direitos Humanos, que toca várias causas e efeitos -, movida pela busca de uma ordem pública que se aproxime em primeiro lugar da proteção dos Direitos Humanos, com vistas a estabelecer um padrão democrático nunca antes vivenciado na região das Américas.

A capacidade de cumprimento, por parte dos Estados Membros, das recomendações e das declarações, emanadas dos diversos órgãos da OEA, e das decisões vinculantes do SIPDH, as quais, em maior e menor grau, influenciam a postura dos sujeitos internacionais diante dos fenômenos da violência e criminalidade, mantém estreita vinculação com os objetivos perseguidos pela OEA nos últimos anos, na perspectiva de superar asatrocidades brutais violações a Direitos Humanos - cometidas nos últimos anos e ainda nos dias de hoje no Continente e de sedimentar valores compatíveis com o pleno respeito à dignidade humana, como condição para o progresso sustentável.

Com fundamento nos casos paradigmáticos a envolver a segurança pública, por meio de raciocínio indutivo, é possível concluir que não se pode falar em ocaso dos Direitos Humanos, ao menos nos países integrantes do SIPDH.

Os exemplos trazidos evidenciam que as muitas tragédias e violações dos Direitos Humanos ocorridas nos dias atuais têm motivado a adoção de inúmeras medidas que visam não apenas ressarcir casos episódicos de vulneração de direitos, mas, sobretudo, a modificar a concepção e o modo de fazer segurança pública, a partir de um novo paradigma - o respeito aos Direitos Humanos de todos, sobretudo da parcela vulnerável da população, comumente vítima das violações de direitos por parte do Estado e de agentes particulares.

Ainda, a partir dos atos analisados, é possível perceber que as lutas políticas a significar e implementar o que se entende por Direitos Humanos não têm arrefecido com a normatização internacional do tema. Ao contrário. Tanto é assim que tem se dado prioridade em tão delicado tema ao combate às violações de direitos das mulheres, pessoas com deficiência, crianças e pessoas encarceradas, etc. 
O conteúdo dos Direitos Humanos está sendo preenchido, na OEA, democraticamente, atendendo dentro do possível os anseios da sociedade civil organizada, de modo a até influenciar o agir dos Estados Membros e suas instituições - tradicionais violadores dos Direitos Humanos -, expondo-os à pressão da Comunidade Internacional por ocasião das condenações e recomendações contra eles proferidas.

Assim, tem prevalecido a força do direito, e não o direito da força na esfera de atuação da OEA em relação aos Direitos Humanos.

Por fim, pontue-se que nada obstante os muitos avanços na proteção internacional dos Direitos Humanos no âmbito da OEA, o que escapa às críticas formuladas no livro em epígrafe, vê-se que ainda se faz imperativo o progresso do SIPDH, a tornar mais efetiva e eficaz sua atuação e cada vez menos dependente da vontade unilateral dos Estados soberanos.

\section{BIBLIOGRAFIA}

AGUADO, Juventino de Castro. Os Tratados internacionais e o processo jurídicoconstitucional. Revista de Direito Constitucional e Internacional. Vol. 65, pág. 311. São Paulo: Revista dos Tribunais, 2008.

ALARCÓN, PIETRO DE JESÚS LORA. Constituição, relações internacionais e aprevalência dos direitos humanos. Revista de Direito Constitucional e Intercional. Vol. 57,pág. 310. São Paulo: Revista dos Tribunais, 2006.

BANCO MUNDIAL. 2011. Crimen y violencia en Centroamérica. Un desafío para el desarrollo. Washington, D.C.

CANÇADO TRINDADE, Antonio Augusto. Tratado de direito internacional de direitos humanos.Vol. II. Porto Alegre: Sergio Antonio Fabris, 2004.

COMISIÓN INTERAMERICANA DE DERECHOS HUMANOS (CIDH). Informe sobre seguridad ciudadana y derechos humanos. Washington, D.C, 2009.

CORPORACIÓN LATINOBARÓMETRO. Informe 2010. Santiago de Chile, 2010.

COSTA, Gino. Segurança Pública e Crime Organizado transnacional nas Américas: Situação e desafios no âmbito interamericano.Revista Brasileña de Seguridad Pública, Sao Paulo, Foro Brasileño de Seguridad Pública, Año 5, n. 8, p. 6-36, feb.-mar.

COSTAS, Douzinas. O fim dos direitos humanos.São Leopoldo/RS. Editora Unisinos, 2009.

DEZEM, Guilherme Madeira. A Corte Interamericana de Direitos Humanos: procedimento e crítica. Revista dos Tribunais. Vol. 844, pág. 11. São Paulo: Revista dos Tribunais, 2006.

JAYME, Fernando Gonzaga. Direitos Humanos e sua efetivação pela Corte Interamericana de direitos humanos. Belo Horizonte: Del Rey, 2005.

MAZZUOLI, Valerio de Oliveira. Processo Civil Internacional no Sistema Interamericano de Direitos Humanos. Revista dos Tribunais. Vol. 895, pág. 87. São Paulo: Revista dos Tribunais, 2010. 
Soberania e a proteção internacional dos direitos humanos: dois fundamentos irreconciliáveis.Revista do Direito Constitucional e Internacional. Vol. 52, pág. 327. São Paulo: Revista dos Tribunais, 2005.

Teoria geral do controle de convencionalidade no Direito brasileiro. Revista dos Tribunais. Vol. 889, pág. 105. São Paulo: Revista dos Tribunais, 2009.

MINISTÉRIO DAS RELAÇÕES EXTERIORES. Conferência Especial sobre Segurança (México, 27 e 28 de outubro de 2003), nota $\mathbf{n}^{\mathbf{0}} \mathbf{3 4 0}$. Disponível em: <http://www.itamaraty.gov.br/sala-de-imprensa/notas-a-imprensa/2003/10/27/conferenciaespecial-sobre-seguranca-mexico-27-e>. Acesso em: 20 jul. 2014.

MIRANDA, Mariana Almeida Picanço de. Poder judiciário brasileiro e a proteção dos direitos humanos: aplicabilidade e incorporação das decisões da Corte Interamericana de Direitos Humanos. Rio de Janeiro: Escola de Direito do Rio de Janeiro da Fundação Getulio Vargas, Centro de Justiça e Sociedade, 2010.

ORGANIZACIÓN DE ESTADOS AMERICANOS (OEA). Informe sobre Seguridad Ciudadana en las Américas 2011. Estadísticas oficiales de Seguridad Ciudadana producidas por los Estados Miembros de la OEA. Washington D.C.

.Declaração sobre Segurança nas Américas.Disponível em: <www.oas.org/documents/por/DeclaracionSecurity_102803.asp>. Acesso em 15 de julho de 2014.

.La Seguridad Pública em las Américas: retos e oportunidades. Disponível em: <http://www.oas.org/dsp/documentos/Observatorio/FINAL.pdf>. Acesso em 16 de julho de 2014.

.La Cárcel: problemas $\mathbf{y}$ desafios para las Américas. Disponível em: <http://issuu.com/flacso.chile/docs/rss_2008_4>. Acesso em 16 de julho de 2014.

.La violência sexual em Latino América y em Caribe: análises de datos secundários.em:<http://www.oas.org/dsp/documentos/Observatorio/violencia_sexual_la_y_c aribe_2.pdf $>$.Acesso em 16 de julho de 2014.

.Informes

de

admissibilidade.em:

<http://www.oas.org/pt/cidh/decisiones/admisibilidades.asp>. Acesso em 22 de julho de 2014.

.Princípios

e boas

práticas.em:

<http://www.oas.org/pt/cidh/decisiones/admisibilidades.asp>. Acesso em 22 de julho de 2014.

PIOVESAN, Flávia. A Constituição de 1988 e os tratados internacionais de proteção dos direitos humanos. Revista de Direito Constitucional e Internacional. Vol. 23, pág. 79. São Paulo: Revista dos Tribunais, 1998.

A proteção internacional dos direitos humanos e o Direitos brasileiro. Revista de Direito Constitucional e Internacional. Vol. 9, pág. 26. São Paulo: Revista dos Tribunais, 1994.

Direitos humanos e direito constitucional internacional. São Paulo: Saraiva. 2009.

Revista de Direito Brasileira | São Paulo, SP | v. 13 | n. 6 | p. 213 - 230 | jan./abr. 2016 
Federalização dos crimes contra os direitos humanos. Revista Brasileira de Ciências Criminais. Vol. 54, pág. 169. São Paulo: Revista dos Tribunais, 2005.

Força integradora e catalizadora dos Sistema Interamericano de proteção dos direitos humanos: desafios para a pavimentação de um constitucionalismo regional. Revista do Instituto dos Advogados de São Paulo. Vol. 25, pág. 321. São Paulo: Revista dos Tribunais, 2010.

PROGRAMA DE LAS NACIONES UNIDAS PARA EL DESARROLLO (PNUD). Venciendo el temor. (In)seguridad ciudadana y desarrollo humanos en Costa Rica. Informe Nacional de Desarrollo Humano 2005. San José de Costa Rica, 2009.

RAMOS, André de Carvalho. Mandados de criminalização no Direito internacional dos Direitos humanos: novos paradigmas da proteção às vítimas de violações de Direitos humanos. Revista Brasileira de Ciências Criminais. Vol. 62, pág. 9. São Paulo: Revista dos Tribunais, 2006.

ROCHA, Fernando Luiz Ximenes. A reforma do Judiciário e os tratados internacionais sobre direitos humanos. Revista dos Tribunais. Vol. 852, pág. 38. São Paulo: Revista dos Tribunais, 2006.

TAMAYO, Carolina Loayza. Aplicaclón de la normatividade protectora de los Derechos Humanos en el Ordenamiento Interno. Revista Brasileira de Ciências Criminais. Vol. 31, pág. 23. São Paulo: Revista dos Tribunais, 2000.

TRANSPARENCY INTERNATIONAL. Barómetro global de la corrupción. UNITED NATIONS OFFICE ON DRUGS AND CRIME (UNODC). 2011. 2011 Global Study on Homicide. Trends, Contexts, Data.Vienna, 2010.

UNODC.A Global Study on Homicide, 2013.Disponível em <http://www.unodc.org/documents/gsh/pdfs/2014_GLOBAL_HOMICIDE_BOOK_web.pdf> . Acesso em 27 de julho de 2014.

VIEIRA, Oscar Vilhena. A Gramática dos Direitos Humanos. Boletim Científico ESMPU, Brasília, Ano 1, n. 4, pág. 13, 2002.

WORLD BANK. Violence in the city.Understanding and supporting community responses to urban violence. Washington, D.C, 2011.

\footnotetext{
${ }^{1}$ a) identificar a vítima; b) recuperar e preservar o material probatóriorelacionado com a morte, com o fim de ajudar em qualquer potencial investigação penal dos responsáveis; c) identificar possíveis testemunhas e obter suas declarações com relação à morte que se investiga; d) determinar a causa, forma, lugar e momento da morte, assim como qualquer padrão ou prática que possa ter causado a morte; e e) distinguir entre morte natural, morte acidental, suicídio e homicídio.

${ }^{2}$ Os dez países que não ratificaram a Convenção Americana de Direitos Humanos são os seguintes: Canadá, Estados Unidos, Antíqua e Barbuda, CommonwealthdasBahamas, Belize, Guiana, Saint Kitts e Nevis, SantaLucia, São Vicente e Granadinas e, por fim, Trinidad e Tobago, que denunciou a Convenção anos após aratificação.
} 